\title{
Efeito de extratos vegetais de plantas do Cerrado para controle de pinta-preta em tomateiro
}

\author{
Bruna Fukumoto Kobayashi1 ${ }^{1}$; Daniel Rufino Amaral ${ }^{1}$
}

${ }^{1}$ Instituto Federal do Triângulo Mineiro - Campus Uberaba, MG, Brasil.

Autor para correspondência: Bruna Fukumoto Kobayashi (brunafkobayashi@hotmail.com)

Data de chegada: 23/05/2016. Aceito para publicação em: 12/07/2017.

$10.1590 / 0100-5405 / 2194$

\section{RESUMO}

Kobayashi, B.F.; Amaral, D.R. Efeito de extratos vegetais de plantas do Cerrado para controle de pinta-preta em tomateiro. Summa Phytopathologica, v.44, n.2, p.189-192, 2018.

A "Mancha de Alternaria" causada pelo fungo Alternaria solani é uma das principais e mais frequentes doenças que incidem na cultura do tomate. Manifesta-se nas hastes, caule e principalmente nas folhas, e em alta severidade. Causa desfolha e também pode provocar infecções nos frutos, tornando-os impróprios para comercialização. Para controle da doença, os defensivos sintéticos ainda são os mais utilizados. Visando a diminuição da toxicidade ao meio ambiente e à saúde humana, surge a busca pela utilização de produtos alternativos para o controle de doenças. O objetivo do trabalho foi avaliar o efeito de extratos vegetais para o controle de Alternaria solani na cultura do tomateiro: in vivo e in vitro. $\mathrm{O}$ experimento foi conduzido em duas etapas: 1- in vivo (em casa de vegetação em sistema hidropônico) e 2- in vitro (em laboratório). Os tratamentos utilizados na primeira etapa foram: 1- Testemunha (sem aplicação); 2- Extrato de Assa peixe; 3- Extrato de Aroeirinha; 4- Extrato de Pata de Vaca do Cerrado; 5- Extrato de Murici, sendo estes na concentração de $10 \%$ do extrato diluído em água e outra testemunha no qual foi aplicado um fungicida (Piraclostrobina). O delineamento experimental foi em blocos ao acaso com quatro repetições. Na segunda etapa, o experimento foi conduzido em delineamento inteiramente casualizado, sendo os mesmos tratamentos da primeira, exceto o tratamento comercial. Observou-se que os extratos a base de Aroeirinha e Assa Peixe, proporcionaram controle de mancha de alternaria em plantas de tomate no experimento in vivo. Já para o experimento in vitro, pode-se observar que o extrato de Murici e Aroeirinha diminuíram o crescimento micelial do fungo.

Palavras-chave: Controle alternativo, Solanum lycopersicon, Alternaria solani, extrato vegetal.

\section{ABSTRACT}

Kobayashi, B.F.; Amaral, D.R. Effect of plant extracts from Cerrado on Alternaria leaf spot control in tomato plants. Summa Phytopathologica, v.44, n.2, p.189-192, 2018.

Alternaria leaf spot caused by the fungus Alternaria solani is one of the main and most frequent diseases that affect tomato crop. It manifests on stalks, stems and especially on leaves, at high severity. It causes defoliation and can also induce infections in the fruits, making them inappropriate for commercialization. To control the disease, synthetic defensives are still the most used products. With the aim of lowering the toxicity to the environment and to the human health, the search for alternative products has emerged. The objective of this study was to evaluate the effect of plant extracts for the control of Alternaria solani in tomato culture: in vitro and in vivo. The experiment was performed in two steps: 1- in vivo (in a greenhouse under hydroponic system) and 2- in vitro (in the laboratory). The treatments used in the first step were: 1- Control (no application); 2- "Assa Peixe" extract; 3- "Aroeirinha" extract; 4- "Pata de Vaca do Cerrado" extract; 5- "Murici" extract, all of which were used at the proportion of $10 \%$ extract diluted with water and another control to which a fungicide (Pyraclostrobin) was applied. Experimental design was in randomized blocks with four replicates. In the second step, the experiment was carried out in completely randomized design, with the same treatments used in the first step, except for the commercial treatment. "Aroeirinha" and "Assa Peixe" extracts provided Alternaria leaf spot control in tomato plants in the in vivo experiment. However, for the in vitro experiment, "Murici" and "Aroeirinha" extracts decreased the mycelial growth of the fungus.

Keywords: Alternative control, Solanum lycopersicum, Alternaria solani, plant extract.

A busca da garantia da qualidade e aparência do produto geralmente leva o produtor a realizar elevadas aplicações de fungicidas e inseticidas para o controle das pragas e doenças responsáveis por danos diretos e indiretos na produção. Entretanto, frustrações nas tentativas de controle reduzem a produção, afetam a qualidade e aumentam os custos de produção (LOPES \& REIS, 2007).

Assim como ocorre em plantios tradicionais, a céu aberto, as doenças são também constantes desafios aos produtores de tomate em cultivos protegidos. Essas doenças normalmente são causadas por bactérias, fungos, nematoides e vírus. Podem ser também provocadas por fatores abióticos, como deficiência ou excesso de nutrientes, fitotoxidez por agrotóxicos e luminosidade inadequada (REIS et al.
2007).

A Pinta-preta, também conhecida como "Mancha de Alternaria" é causada pelo fungo Alternaria solani e é uma das principais e mais frequentes doenças que ocorrem em todas as regiões produtoras de tomate no Brasil (PEREIRA, et al. 2013).

A utilização de agrotóxicos pode causar o desenvolvimento de resistência em patógenos, pragas e em plantas invasoras a certos princípios ativos dos agrotóxicos; o surgimento de doenças; o desequilíbrio biológico, alterando a ciclagem de nutrientes e da matéria orgânica; a eliminação de organismos benéficos e a redução da biodiversidade. O principal fator responsável pelos problemas acima mencionados está relacionado ao fato desses produtos serem, 
muitas vezes, aplicados em doses excessivas ou de forma inadequada (BETTIOL \& MORANDI, 2009).

Para Santos et al. (2013), na busca de alternativas de controle, extratos de plantas têm sido utilizados com maior abrangência. Quando comparados aos produtos sintéticos, oferecem grandes vantagens, tais como: a geração de novos compostos, os quais os patógenos não são capazes de inativar, além de serem menos tóxicos, de rápida degradação no ambiente, apresentarem amplo modo de ação e serem derivados de recursos renováveis.

Os extratos vegetais podem apresentar potencial inseticida, fungicida, herbicida e nematicida, sendo considerados de boa eficiência (SANTOS, 2013). Uma das funções das substâncias que compõem estes extratos (metabólitos secundários) é fornecer proteção às plantas contra $o$ ataque de organismos patogênicos (SILVA et al., 2005).

O uso de biofungicidas, extratos vegetais e óleos essenciais, têm sido relatados como potentes fungicidas e inseticidas naturais, onde os resultados alcançados nessa linha de pesquisa têm-se mostrado promissor para uma utilização prática no controle de fitopatógenos (FRANCO \& BETTIOL, 2000). Diante do exposto, o presente trabalho teve o objetivo de avaliar o efeito de extratos vegetais para controle de Alternaria solani na cultura do tomateiro: in vivo e in vitro.

\section{MATERIAL E MÉTODOS}

$\mathrm{O}$ experimento foi realizado em duas etapas. Na primeira etapa: in vivo e na segunda: in vitro. As plantas utilizadas como extrato vegetal foram escolhidas com critério de origem e abundância no local, sendo requisito na obtenção de produtos à base de extratos vegetais, correspondendo a fácil aquisição e derivadas de fontes renováveis. Foram escolhidas plantas do Cerrado Mineiro encontradas no Instituto Federal de Educação, Ciência e Tecnologia do Triângulo Mineiro (IFTM Campus- Uberaba), no município de Uberaba, MG, assim sendo: Assa Peixe (Vernonia polysphaera); Aroeirinha (Schinus polygama); Pata de Vaca do Cerrado (Bauhinia forficata) e Murici (Byrsonima crassifolia).

A preparação dos extratos vegetais utilizados nas etapas 1 e 2 foi realizada através do Método de Infusão. Após a coleta de folhas, estas foram expostas ao meio com temperatura ambiente em torno de $25^{\circ} \mathrm{C}$ para secagem natural. Após secagem, foram separadas folhas dos galhos, mantendo-se somente as folhagens que foram submetidas à trituração. Após essa etapa, o material triturado foi devidamente pesado, realizando-se proporção de 100 gramas do material vegetal diluído em 1 litro de água fervente. Logo, uma concentração de 10\% do extrato vegetal.

Estando as folhas completamente trituradas, durante o processo de infusão, o material vegetal foi imerso em água fervente, e transferido para recipiente vedado, ficando em "over night". Após o processo de infusão das folhas, o material foi devidamente filtrado em peneiras de 4 mm e reservados em recipiente plástico. Para conservação, os extratos vegetais foram mantidos em congelador.

Na primeira etapa, o experimento foi conduzido em hidroponia, no setor de Olericultura localizado no Instituto Federal de Educação, Ciência e Tecnologia do Triângulo Mineiro (IFTM Campus - Uberaba), no município de Uberaba, MG. O mesmo está localizado a $800 \mathrm{~m}$ de altitude, com latitude de $19^{\circ} 39^{\prime} 19^{\prime}$ 'S e longitude de $47^{\circ} 57^{\prime} 27^{\prime \prime} \mathrm{W}$. O clima do local, segundo a classificação internacional de Köppen é do tipo Aw, isto é, tropical quente úmido, com inverno frio e seco com precipitação e temperatura média anual de $1571 \mathrm{~mm}$ e $22,3{ }^{\circ} \mathrm{C}$, respectivamente (CLIMATE, 2016).

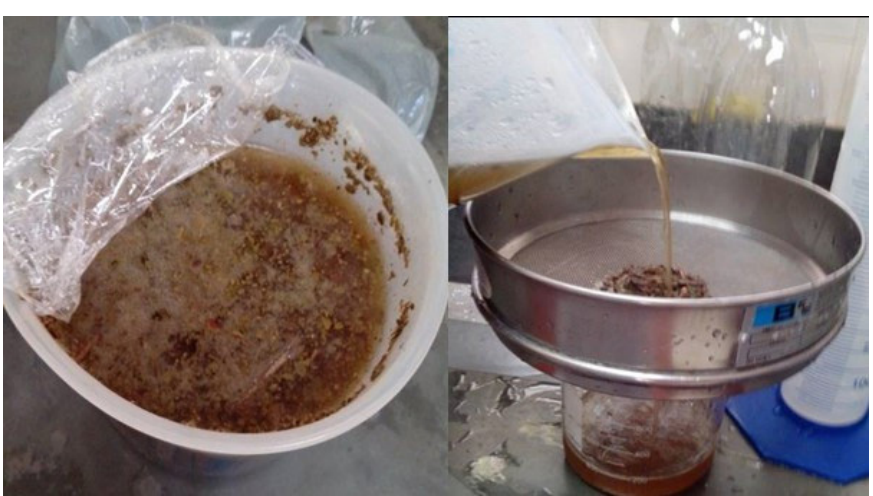

Figura 1. Obtenção do extrato vegetal e filtragem

O delineamento experimental foi em blocos ao acaso (DBC) com quatro repetições e nove plantas por parcela. Os tratamentos foram: 1-Testemunha (sem aplicação); 2- Extrato de Assa peixe (Vernonia polysphaera); 3- Extrato de Aroeirinha (Schinus polygama); 4- Extrato de Pata de Vaca do Cerrado (Bauhinia forficata); 5- Extrato de Murici (Byrsonima crassifolia), e outra testemunha no qual foi aplicado um fungicida sintético, 6- Piraclostrobina.

As aplicações dos produtos à base de extrato vegetal foram realizadas com pulverizador costal de $\mathrm{CO}_{2}$ experimental fabricado no Instituto Federal do Triângulo Mineiro Campus Uberaba, em intervalos de 15 dias.

$\mathrm{Na}$ etapa 1 , in vivo, para verificação do efeito de extratos contra o fungo causador da Mancha de Alternária, foram realizadas cinco avaliações semanais, utilizando-se a escala diagramática de Boff (1988) de acordo com a severidade da doença, e análise da severidade calculada pela AACPD.

Foi realizada avaliação da severidade da doença no terço médio e inferior das plantas escolhendo-se um trifólio aleatório, avaliado de acordo com a escala diagramática de Boff (1988), sendo esta descrita por notas de 1 a 6: 1 - Ausência de sintomas; 2 - traços de sintomas a 4\% de severidade; $3-4,1$ a $8 \%$; 4- 8 a $16,1 \%$; 5 - 16,1 a $32 \%$; 6- acima de $32 \%$. Após avaliação pela escala diagramática com notas, estas foram convertidas a porcentagem e realizado cálculo da Área Abaixo da Curva de Progresso da Doença (AACPD). Segundo Shaner \& Finney (1977), a área abaixo da curva de progresso da doença pode ser calculada da seguinte forma:

$\mathrm{AACPD}=\sum=\mathrm{ni} 1[(\mathrm{Yi}+1+\mathrm{Yi}) / 2][\mathrm{Xi}+1-\mathrm{Xi}]$

Em que:

Yi: severidade da doença (nota por parcela em \%) na iésima observação;

Yi+1: severidade da doença na época da avaliação i+1;

Xi: tempo (dias) na iésima observação;

$\mathrm{Xi}+1$ : época da avaliação $\mathrm{i}+1$;

n: número total de observações.

Foi avaliada a Área Abaixo da Curva de Progresso da Doença (AACPD) do terço médio e inferior das plantas em relação ao extrato vegetal utilizado.

Os dados obtidos foram submetidos à análise de variância por meio da aplicação do teste $\mathrm{F}$ e na ocorrência de diferenças de ordem significativa os dados foram submetidos ao teste de Scott-Knott a 5\% de probabilidade.

$\mathrm{Na}$ segunda etapa, in vitro, inicialmente foram preparadas placas de Petri em meio BDA (Batata-Dextrose-Águar), sendo adicionado o extrato vegetal nesse meio obtendo-se concentração de $10 \%$ do extrato vegetal. Em seguida, foram conservadas em câmara Incubadoras de 
Demanda Bioquímica de Oxigênio (Incubation Biochemical Oxygen Demand - BOD) sob temperatura de $13^{\circ} \mathrm{C} \pm 2$.

O fungo (Alternaria solani), foi obtido da micoteca do IFTM Campus Uberaba, de mesma origem. O fungo conservado em óleo mineral foi repicado para placas de Petri contendo meio BDA, e mantido em BOD por 7 dias até que completassem crescimento completo para utilização.

Após obtenção do inóculo em placas de Petri, foi utilizado o cortador de Cobre, esterilizado para extrair disco do fungo e, com o auxílio da pinça era depositada na placa de Petri com meio BDA e extrato vegetal. Finalizado esse processo, as placas foram conservadas em BOD, para o crescimento fúngico.

$\mathrm{Na}$ segunda etapa do experimento, foram utilizadas BOD, com fotoperíodo variando entre 9 e 10 horas de escuro e temperatura de 23 a $25^{\circ} \mathrm{C}$, na qual eram conservadas as placas de Petri para cultivo dos fungos.

O delineamento experimental foi realizado em blocos inteiramente casualizados, com 10 repetições em cada um dos tratamentos. Foram utilizados os mesmos tratamentos da etapa 1 (in vivo) na mesma concentração de $10 \%$ do extrato vegetal, excluindo-se o tratamento com fungicida comercial.

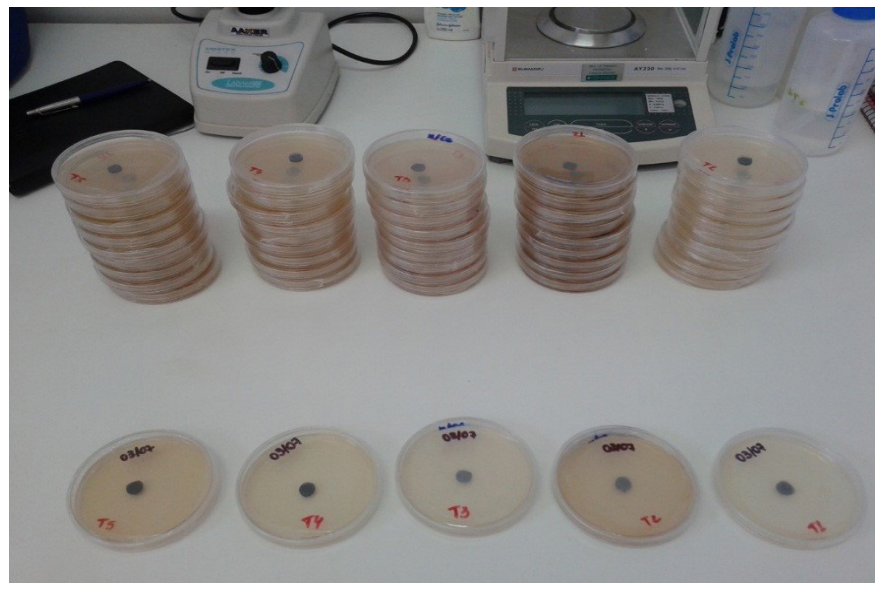

Figura 2. Placas de Petri com tratamentos e repetições.

As placas acondicionadas em BOD, foram avaliadas por medição do crescimento do fungo todos os dias com auxílio de régua.

A característica avaliada nessa segunda etapa foi o Índice de Crescimento Micelial (ICM) do fungo de acordo com o tratamento utilizado, objetivando-se avaliar qual produto a base de extrato vegetal era capaz de inibir ou retardar o desenvolvimento do fungo.

O ICM segundo conforme a fórmula descrita por Oliveira (1991) é dado:

$\mathrm{ICM}=\Sigma(\mathrm{D}-\mathrm{Da}) / \mathrm{N}$

Sendo:

$\mathrm{ICM}=$ índice de crescimento micelial

$\mathrm{D}=$ diâmetro médio atual da colônia $(\mathrm{mm})$

$\mathrm{Da}=$ diâmetro médio da colônia do dia anterior $(\mathrm{mm})$

$\mathrm{N}=$ número de dias após a inoculação

$\mathrm{O}$ experimento foi conduzido até que o fungo presente na testemunha atingisse a borda da placa de Petri $(80 \mathrm{~mm})$. O Índice de Crescimento Micelial foi avaliado em relação ao extrato vegetal utilizado. Os dados obtidos foram submetidos à análise de variância por meio da aplicação do teste $\mathrm{F}$ e na ocorrência de diferenças de ordem significativa os dados foram submetidos ao teste de Scott-Knott a 5\% de probabilidade.

\section{RESULTADOS E DISCUSSÃO}

Na tabela 1, pode-se observar que existem diferenças para os valores de severidade nas folhas, decorrentes, provavelmente, do efeito dos extratos de Aroeirinha e Assa Peixe, apresentando melhores resultados, com valores de AACPD de severidade 67,37 e 77,87, respectivamente, sendo equivalentes ao tratamento comercial, Piraclostrobina, com valor de AACPD de 73,72. Estes se apresentaram estatisticamente diferentes dos demais, os quais não se diferiram entre si.

Tabela 1. AACPD para o terço inferior das plantas em função dos tratamentos utilizados. Uberaba, 2014.

\begin{tabular}{lc}
\hline Tratamentos & AACPD \\
\hline Aroeirinha & $67,37 \mathrm{a}^{1}$ \\
Piraclostrobina & $73,72 \mathrm{a}$ \\
Assa Peixe & $77,87 \mathrm{a}$ \\
Testemunha (sem aplicação) & $89,47 \mathrm{~b}$ \\
Pata de Vaca do Cerrado & $93,72 \mathrm{~b}$ \\
Murici & $101,47 \mathrm{~b}$ \\
\hline CV(\%): & 18,46 \\
${ }^{1}$ Médias seguidas da mesma letra na vertical não diferem entre si a 5\% de \\
probabilidade, pelo Teste Scott- Knott.
\end{tabular}

Resultados encontrados por Garcia et al. (2012), para extrato de aroeirinha contra Sclerotinia sclerotiorum, se mostram diferentes para os obtidos neste trabalho. Aroeirinha, jambolão, alfavaca, mandioca e losna não diferiram da testemunha (sem aplicação), proporcionando pouco efeito sobre o supracitado fitopatógeno, o extrato dessa planta não surtiu efeito algum sobre o seu crescimento.

Os tratamentos com extrato vegetal a base de Pata de Vaca do Cerrado e Murici, apresentaram valores de AACPD de 93,72 e 101,47, respectivamente, enquanto a testemunha, sem aplicação de qualquer produto, apresentou 89,47 com o valor de $\mathrm{AACPD}$, mostrando que não houve efeito desses extratos no controle da doença.

A partir da tabela 2, pode-se observar que os tratamentos com extrato vegetal a base de Aroeirinha e Assa Peixe, com valores de AACPD de 36,51 e 40,38, respectivamente, além dos tratamentos sem aplicação (testemunha) e padrão comercial (Piraclostrobina), com valores de 38,60 e 41,43, respectivamente, apresentaram-se melhores que os demais tratamentos, porém indiferentes entre si.

Tabela 2. AACPD avaliando-se o terço médio das plantas em função dos tratamentos utilizados. Uberaba, 2014.

\begin{tabular}{lc}
\hline Tratamentos & AACPD \\
\hline Aroeirinha & $36,51 \mathrm{a}^{1}$ \\
Testemunha (sem aplicação) & $38,60 \mathrm{a}$ \\
Assa Peixe & $40,80 \mathrm{a}$ \\
Piraclostrobina & $41,43 \mathrm{a}$ \\
Pata de Vaca do Cerrado & $49,00 \mathrm{~b}$ \\
Murici & $53,16 \mathrm{~b}$ \\
\hline CV(\%): & 19,01 \\
\hline
\end{tabular}

${ }^{1}$ Médias seguidas da mesma letra na vertical não diferem entre si a 5\% de probabilidade, pelo Teste Scott- Knott.

No entanto, os tratamentos utilizando-se extratos a base de Pata de Vaca do Cerrado e Murici, com valores de 49,0 e 53,16, respectivamente, apresentaram resultados desfavoráveis e com índices 
de severidade da doença mais elevados que os demais tratamentos, não havendo também diferença estatística entre eles.

Para o índice de Crescimento Micelial (ICM), na tabela 3, que os tratamentos com produtos à base de extratos vegetais de Murici e Aroeirinha, com valores de ICM de 56,0 e 59,0, apresentaram melhores resultados quando comparados aos demais tratamentos. Já o tratamento com produto a base de extrato vegetal de Assa Peixe, diferiu-se do restante dos tratamentos, podendo ser compatível aos resultados da fase 1 (in vivo), em que este tratamento apresentou melhores resultados quando avaliado a AACPD do terço inferior e terço médio das plantas.

A interação entre as duas fases do experimento, resulta na hipótese de que produtos à base de extrato vegetal podem inibir ou retardar o crescimento micelial do fungo Alternaria solani na cultura do tomateiro.

Tabela 3. ICM do fungo Alternaria solani na cultura do tomateiro em função dos tratamentos.

\begin{tabular}{lc}
\hline Tratamentos & ICM \\
\hline Murici & $56,00 \mathrm{a}^{1}$ \\
Aroeirinha & $59,30 \mathrm{a}$ \\
Assa Peixe & $73,70 \mathrm{~b}$ \\
Testemunha & $80,00 \mathrm{c}$ \\
Pata de Vaca do Cerrado & $80,16 \mathrm{c}$ \\
\hline CV $(\%):$ & 7,2
\end{tabular}

${ }^{1}$ Médias seguidas da mesma letra na vertical não diferem entre si a $5 \%$ de probabilidade, pelo Teste Scott- Knott.

No entanto, o tratamento com produto a base de extrato vegetal de Pata de Vaca do Cerrado, com valor de ICM de 80,0, foi equivalente à Testemunha sem qualquer aplicação de qualquer produto, com valor de 80,15 de ICM. Estes tratamentos apresentaram resultados menos satisfatórios, não havendo diferença estatística entre si.

É possível concluir, a partir das condições do presente trabalho, que os extratos vegetais de Aroeirinha e Assa Peixe, diminuem a severidade da Mancha de Alternaria na cultura do tomateiro, em Uberaba, MG.

Já os produtos à base de extratos de Aroeirinha e Murici, tem ação direta sobre Alternaria solani, retardando ou impedindo seu crescimento in vitro.

\section{REFERÊNCIAS}

1. Boff, P. Epidemiologia e controle químico da mancha de estenfílio (Stemphylium solani Weber) e da pinta preta (Alternaria solani (Ellis \& Martin) Jones \& Grout) em dois sistemas de condução do tomateiro (Lycopersicon esculentum Mill.). 1988. 192p. Dissertação (Mestrado em Agronomia/Fitopatologia) - Universidade Federal de Viçosa, Viçosa.

2. Bettiol, W.; Morandi, M.A.B. (Ed.). Biocontrole de doenças de plantas: uso e perspectivas. Jaguariúna: Embrapa Meio Ambiente, 2009. 332p.

3. Climate-Data Org. Clima-Uberaba. Uberaba, 2016. Disponível em: $<$ http:// pt.climate-data.org/location/2878/>. Acesso em: 22 abr. 2016.

4. Franco, D.A.; Bettiol, W. Controle de Penicillium digitatum em pós- colheita de citrus com produtos alternativos. Fitopatologia Brasileira, Brasília, DF, v.25, p.602-606, 2000.

5. Garcia, R.A.; Juliatti, F.C.; Barbosa, K.A.G.; Cassemiro, T. A. Atividade antifúngica de óleo e extratos vegetais sobre Sclerotinia sclerotiorum. Bioscience Journal, Uberlândia, v.28, n.1, p.48-57, 2012.

6. Lopes, C.A.; Reis, A. Doenças do tomateiro cultivado em ambiente protegido. Brasília, DF: Embrapa Hortaliças, 2007. 17p. (Circular Técnica, 100).

7. Oliveira, J.A. Efeito do tratamento fungicida em sementes no controle de tombamento de plântulas de pepino (Cucumis sativo L.) e pimentão (Capsicum annanum L.). 1991. 111f. Dissertação (Mestrado em Fitossanidade) - Escola Superior de Agricultura de Lavras, Lavras.

8. Pereira, R.B.; Fernandes, F.R.; Pinheiro, J.B. Manejo da pinta preta: uma ameaça às lavouras de tomateiro a céu aberto. Brasília, DF: Embrapa Hortaliças, 2013. 5p. (Comunicado Técnico, 95).

9. Reis, A.; Café Filho, A.C.; Henz, G.P. Phytophthora capsici: patógeno agressivo e comum às solanáceas e cucurbitáceas. Brasília, DF: Embrapa Hortaliças, 2007. 8p. (Circular técnica, 5).

10. Santos, P.L.; Prando, M.B.; Morando, R.; Pereira, G.V.N.; Kronka, A. Z. Utilização de extratos vegetais em proteção de plantas. Enciclopédia Biosfera, Goiânia-GO, v.9, p.2562-2576, 2013.

11. Scramin, S.; Zavatti, L.M.S.; Silva, H.P.; Yhan, C. Utilização de extratos vegetais no controle de dois nematoides fitopatogênicos - Meloidogyne incognita e Tylenchulus semipenetrans. In: Workshop sobre produtos naturais no controle de pragas, doenças e plantas daninhas, n. 1, 1990, Jaguariuna. Anais. Jaguariuna: Embrapa, 1990.

12. REIS, A.; CAFÉ FILHO, A. C.; HENZ, G. P. Phytophthora capsici: patógeno agressivo e comum às solanáceas e cucurbitáceas. Brasília, DF: Embrapa Hortaliças, p. 8, 2007 (Embrapa Hortaliças. Circular técnica, 5).

13. Shaner, G.; Finney, R.E. The effect of nitrogen fertilization on the expression of slow-mildewing resistance in knox wheat. Phytopathology, St. Paul, v.67, n.8, p.1051-1056, Aug. 1977.

14. Silva, M.B.; Rosa, M.B.; Brasileiro, B.G.; Almeida, V.; Silva, C.C.A. Desenvolvimento de produtos à base de extratos de plantas para o controle de doenças de plantas. In: Venezon, M.; Paula Jr., T.J.; Pallini, A. (Ed.). Controle alternativo de pragas e doenças. Viçosa: EPAMIG/CTZM, 2005. p.221-246. 